\title{
The vocational education Recessive system produced Game Theory abalysis

\author{
Wang DongLing
}

Department ofeconomics and management, Shandong Yingcai University, Jinan,

251400, China

email: 40668058@qq.com

\section{Keywords:Recessive system;Game Theory;Strong leading}

\begin{abstract}
China is a country with an emphasis on knowledge but Contempt skills,Since the Chinese economic reform.Due to the imbalance in the existence and development of China's general education and vocation education.Due to the imperfection of system,the expected return of Vocation education is significantly worse than general education's.This makes people not paid attention to vocational education.In terms of the development of vocational education.Compare with any interest subject,government always pay a strong role in Game Theory.
\end{abstract}

\section{Introduction}

Recently, the quantity of studies on the vocational education scholars and organizations is multitudinous, but the researchers more are conduct the research from the macroscopic stratification plane to central authorities' policy formulation and the system construction, and paying little attention to regarding the direct relation local authority's policy research with the vocational education.Although National People's Congress and government's department has made the investigation and study about the development condition on various provinces vocational education.however, the administrative investigation and study time is quite short and lacks to the vocational education and the local authority policy relevant research, has neglected the different system and the policy which the local authority formulates is different regarding the different type countryside vocational education influence.In fact, the development of the vocational education system environment and the policy environment grows in different types of vocational education and local government's interactions, and the two sides there is interaction and relationships with impact, but the current level of researchers concern less on this point. The system for research also mainly limited to text, to find out more about the live systems, namely the hidden the informal systems, to the neglect of local governments in the systems and policies in the implementation of the modifications of the phenomenon of concern, thus the concerns of vocational education in the formulation and implementation of a system of hidden become the focus of our research. This article with the introduction of the game theory in an attempt to explain the underlying causes of vocational education system of hidden root causes.

\section{Game Theory}

Game Theory is a special example of a complete information static game.For example, there is a big pig and a small pig.One head is a Pig trough, another head is provided with a supply of pig feed control button, click the button will have 10 units slops into the trough, but who press the button will first pay the cost of 2 units,if the first to the side is the big pig,The size of the pig to eat food income than is 9:1; At the same time to the side of the groove, the income ratio is 7:3; if the pig to the trough first, the income ratio is 6:4. According to the hypothesis, the game can be written in the following game standard type. 


\begin{tabular}{|c|c|c|}
\hline Small pig & Action & Waiting \\
\hline Big pig & & 4,4 \\
\hline Action & 5,1 & 0,0 \\
\hline Waiting & $9,-1$ & \\
\hline
\end{tabular}

Observation the game matrix we can know due to $1<4$ and $-1<0$, so the pig only choose to wait for the strategy. Meanwhile,for the big pig, only action is the best choice. Therefore, there is only Nash equilibrium $(4,4)$ in this game.

\section{The leading role of the Strongest}

The Central Government in the vocational education policy implementation game played the strong role in the "pig gaming" . Of course ,it's vary. The central government is not only those who participated in the game,but also they are the rules of the Game's Designer. Thus, while the analysis of the front of the game, the Central Government is directly involved in the game with local governments. But regardless of the game between the local government, as well as the schools and enterprises of coordination between the game,it is a critical component of the rules established by the central government. Game between the local government, the central investigation department of the probability of punishment $F$ is reflected by the participation of the central government.Subsidies is the expression Central Government can participate in schools and enterprises' gaming. Only designing a good incentive mechanisms can make it possible for the other participants more initiatives taken by the policy. Therefore, the central government is not only a manifestation of the dominant position and the Game Theory the strong action, but also in the form of subsidized with a means of inflicting punishment in order to change other gaming participants gain function, which in turn affects action policy. Large, medium and small enterprises and vocational schools can be removed from the Game Theory model. Large enterprises is the Game Theory model of the powerful, and the small enterprises is weak. Although the various types of business can cultivate talents in the result of the proceeds, but each of the proceeds derived from, and the cost is likely to be different. Large enterprises need talented people as a result of large size, the treatment and protection of relatively good condition and therefore to attract more talents to the enterprise work, enterprises can obtain greater benefits. In the case of small and medium-sized enterprises, and as a result of paying the cost more, rather less in need of qualified personnel as a result of or could not attract more people to their enterprise and the proceeds will be much smaller, and even with pay will be compared to the cost of benefits for Therefore, from this point of view, the Government should be based on the size of the type of business, produce different gaming strategy that allows different companies to have a relatively equitable benefits.

\section{Vocational education recessive system question root discussion answer}

Through the modeling and analysis of the policy implementation, it can be seen that the final equilibrium result of the policy implementation is decided by the game rules and the parameter conditions. Any game behavior, are subject to the rules.And policy implementation as an important part of the government to implement the expression of the will of the state, of course subject to the national system and specific institutional arrangements.From the study of human factors, although the traditional culture also affect people's perceptions and choices, but this effect is also produced by the basic demands and analysis of the interests of the people. Under the current institutional arrangements, the vocational education talent cultivation in reality in the social stratification status affects people's choice, the nature of the pursuit of the interests of the people determines the individual in the society under the conditions with resources only to vocational education as a second choice, or not has the choice of. And from the enterprise, local governments at all levels, in 
the pursuit of maximizing the interests of the premise, must be the government to develop a complete system of measures to be able to balance the game on the Nash equilibrium.

\section{Perfect system angle of view: Atonement income loss}

Interest is the prerequisite for gaming. In vocational education policy implementation process, due to the subjects of interest through the implementation of the policies of the expected benefits of the relatively low, leads to participation in the development of the vocational education initiative are to produce various policy block behavior. According to the vocational education policy implementation in the course of the principal bodies of interests have been analyzed the game, the game rules and parameters for the outcome of the game has a decisive impact, which in turn requires a vocational education system of the policy environment must be complete and effective, the only way to guarantee that the effectiveness of the implementation of the policy. While the establishment and improvement of the system of the basis of the interests was to make up for the loss of revenue. The Game Theory model analysis can also be used to explain the present social individual choice of vocational education of hesitation and contradictions, the expected gains less is the root cause. In the game on the model, the score lower students can be seen as a small pig, pig can have two options, one is not to accept any education direct employment may be given the low profitability, the cost of 1 to 0 ; the second is receiving vocational education, you can get the expected gains, but at the same time to pay a fixed cost.If the profit is greater than the costs of 1 , students choose vocational education; But if the gains from below costs, certainly will reduce the enthusiasm of students to receive vocational education. So, to individuals, whether to choose the vocational education, the important influence factors is to pay the cost after access to higher income. The development of vocational education is beneficial to the development of the society public activities, with the public welfare, so from the government should from the lower students from the perspective of education cost and increase revenue to influence student's choice. And from the Angle of increasing income, not only to improve the wages of skilled talents, and to improve the teaching quality of vocational education, can let the students pay cost after both to the nature of higher revenues, also to obtain certain dominant earnings.

For all levels of local government and enterprise, also is such. Due to local governments at all levels carry out the policies of the vocational education can't direct economic benefits, also is very uneven regional economic development, so the central government can make up for the revenue loss from perspective, for the implementation of vocational education policy effective fiscal subsidies for local government, to improve policy objectives; To participate in vocational education activities of enterprises for fiscal support, tax support and affirmation of the other way, so as to improve the income of enterprises, it will also boost the enthusiasm of the enterprise executive policy and effectiveness.

\section{Strengthening of institutions subject: strengthen the leading role of the Government}

Reform and opening up in the past 30 years, my vocational education development achievements can be clearly demonstrated that the Government and give full play to the leading role of vocational education policy implementation is critical. In the interests of the pluralism of the local governments at all levels, from the public interest, in the interests of the Organization as well as the individual interests of a policy on the implementation of a conflict of interest is inevitable. In addition, the Government of the unwieldy, ineffectiveness and the one-sided pursuit of scale and speed of development such as protectionist tendencies would be of vocational education have a negative effect in the implementation of policies. In the face of these problems, we should give full play to the leading role of the government, improving the effectiveness of the implementation of the policy is to strengthen the central government to maintain public interest functions, called for the governments at all levels from the national interests and the interests of the whole perspective interest contradictions and conflicts, and assume its responsibility for the maintenance of social and public interests of the duty to strengthen the allocation of resources, improve their own 
administrative efficiency and on vocational education policy objectives.

In the process of establishing market economy system in China, the vocational education management system reform step by step, also part of the administrative power gradually down to the local government. But have been so far, more than vocational education management problem remains unresolved.Under the influence of education industrialization, the development of vocational education in China has showed the trend of marketization, thereby seriously affecting the effects of policy implementation. Funds investment insufficiency, the educational condition is poorer, lack of teachers has become many vocational schools, especially in the west, the common problems in rural vocational schools. Vocational education policies and measures of policy execution, as a result of imperfect perfunctory, distortion is the outstanding problem in the process of policy implementation. Therefore, strengthening the leading role of government, perfect the policy enforcement mechanism, is necessary for improving the effectiveness of policy execution.

\section{The new system concept: policy implementation mechanisms established infrastructure}

Due to the local government's primary responsibility is develop vocational education, so how to deal with the relationship between the central government and local government must be taken into account when improves the process of the system.According to the principal-agent theory in economics,. The representatives of the people of all levels of local people's Congress has not formed an effective supervision and control of the same level of government,in this case,In fact, the central government has become a real client, and it is difficult for the people to realize their own right of trust and supervision. So in our country, based on the separation of powers between the central and local governance, institutional arrangements, the central government and provincial government constitute the principal-agent relationship, by analogy, lower levels of government and the governments at higher levels respectively form the principal - agent relation. In fact, the central government has become a real client, and it is difficult for the people to realize their own right of trust and supervision. So in our country, based on the separation of powers between the central and local governance, institutional arrangements, the central government and provincial government constitute the principal-agent relationship.Under this kind of relations, local government officials will exert discretion, through projects to seek personal position promotion; At all levels, local governments in order to meet the need to maximize their own interests,Inevitably increase the competition for financial interests, And the limited resources into the most significant areas of economic efficiency.Therefore, for facilitating policy Effectively implement, the establishment of an effective policy implementation mechanism, The improvement of government administrative power allocation, establishing and perfecting the supervision mechanism, responsibility mechanism, evaluation mechanism of government officials is necessary.

\section{Conclusion}

The establishment of any system and mechanism is under the guidance of a certain idea.The establishment of vocational education policy implementation mechanism must conform to the vocational education's development of law,In line with the value orientation of vocational education, and based on the principle of balance of interests to achieve the policy objectives.Policy implementation mechanism is the carrier of the whole policy life process system, is through the power division in the organization structure, management system based on the implementation of policy implementation, monitoring and control until the realization of the policy objectives of the organic whole.Among them, the idea decides the value choice of policy implementation and the principle of value distribution, and the system is the foundation and guarantee for the implementation of this choice and distribution.Therefore, the concept of innovation system is the foundation of the establishment of the mechanism.

Funds support: National Education Science Program（DFA1418） 


\section{Reference:}

[1]Yahong Zhou, Lingli Xu, Zhengqing Xia. From the countryside vocational education looked the human capital - - analyzes to the countryside family contribution based on the northern Jiangsu countryside family microscopic data( real diagnosis). Economical research[J], 2010,08:55-65.

[2]Nan Li. Since reform and open policy our country countryside vocational education policy research[D]. northeast normal university, 2013.

[3]Liyue Zhang.Our country countryside vocational education difficult position studies[D]. northeast normal university, 2008.

[4]Jie Zhou.Our country countryside vocational education policy value studies[D]. Henan University, 2010.

[5]Huan Wang.The our country countryside vocational education resources disposition main question searches analyzes[J]. Education development research, 2012,01:18-23. 